2015-04-01

\title{
Equity as a Prerequisite for Stability of Cooperation on Global Public Good Provision
}

\section{Buchholz, W}

http://hdl.handle.net/10026.1/8309

10.1007/s10640-015-9907-z

Environmental and Resource Economics

Springer Science and Business Media LLC

All content in PEARL is protected by copyright law. Author manuscripts are made available in accordance with publisher policies. Please cite only the published version using the details provided on the item record or document. In the absence of an open licence (e.g. Creative Commons), permissions for further reuse of content should be sought from the publisher or author. 


\title{
Equity as a Prerequisite for Stability of Cooperation on Global Public Good Provision
}

\author{
by
}

Wolfgang Buchholz

University of Regensburg, Department of Economics and Econometrics, 93040 Regensburg, Germany, and CESifo Munich, Germany

e-mail: wolfgang.buchholz@ur.de

Alexander Haupt

Plymouth University, Plymouth Business School and Plymouth Graduate School of Management, Drake Circus, Plymouth PL4 8AA, United Kingdom, and CESifo Munich, Germany

e-mail: alexander.haupt@plymouth.ac.uk

Wolfgang Peters

European University Viadrina, Faculty of Business Administration and Economics, 15230 Frankfurt (Oder), Germany

e-mail: peters@europa-uni.de

\section{March 2015}

This paper is accepted for publication in Environmental and Resource Economics. The final publication is available at link.springer.com: http://dx.doi.org/10.1007/s10640-015-9907-z

Keywords: Public Goods, Core, Equity, Stability of Cooperation

JEL Classification: C71, D63, H41

Abstract: Analysing cooperative provision of a global public good such as climate protection, we explore the relationship between equitable burden sharing on the one hand and core stability on the other hand. To assess the size of the burden which a public good contribution entails for a country, we make use of a specific measure based on Moulin (1987). In particular, we show that a Pareto-optimal allocation which is not in the core can always be blocked by a group of countries with the highest Moulin sacrifices. In this sense, it is the 'overburdening' and thus 'unfair' treatment of some countries that provides the reason for core instability. By contrast, a Paretooptimal allocation is in the core if the public good contributions are fairly equally distributed according to their Moulin sacrifices. The potential implications of our theoretical analysis for global climate policy are also discussed. 


\section{Introduction}

Achieving Pareto-efficient public good allocations is a challenging task, particularly at the international stage. Without a central authority or common institutions which can enforce contributions of countries to the funding of international public goods, their efficient provision hinges on maintaining voluntary cooperation of all countries. Consequently, the stability of coalitions is key to successful cooperation on public good provision, with climate protection being one of the most prominent examples. ${ }^{1}$

On a basic level, stability means that member countries do not prefer breaking away from a coalition. To make this precise, several stability concepts have been suggested in the literature (see Finus, 2001, 2008, Ray, 2007, or Eyckmans, 2012, for overviews). One of the most prominent is the classical concept of core stability, where a Pareto-optimal allocation is said to lie in the core if no sub-coalition of countries is able to improve the welfare of all its members by abandoning the original allocation and generating a new standalone allocation. ${ }^{2}$ Different assumptions can be made about the behaviour of the remaining countries after separation of the sub-coalition from the whole group of countries, leading to various specifications of the core concept (see, e.g., Moulin, 1995, or in the context of international environmental cooperation Finus, 2001, pp. 245254).

The core concept, however, is not only important for the stability of international agreements on global public good provision but also for the determination of the possible outcomes of international negotiations over global public good provision. As bargaining outcomes require unanimous approval of all signatories, any allocation outside the core will be rejected by at least some group of countries. These blocking countries can increase their welfare by forming a sub-coalition and signing an alternative agreement with only limited participation. On the one hand, an efficient provision of the public good thus can only be expected as the bargaining outcome of a grand coalition if the resulting allocation lies in the core. On the other hand, a bargaining outcome will only be accepted by the parties if it satisfies certain criteria of distributional justice (see, e.g., Ringius, Torvanger and Underdal, 2002, Lange, Vogt and Ziegler, 2007, Posner and

\footnotetext{
${ }^{1}$ The prospect of international cooperation on environmental issues and the stability of cooperation also depend, to some degree, on the environmental policy instruments that are applied. See, e.g., Endres and Finus (1999) who analyse how the instrument choice affects the success of international environmental agreements. This aspect will, however, not be considered further in this paper.

${ }^{2}$ The seminal application of the core concept to public good economies is Foley (1970). For treatments of the core in general public good economies, see also Myles (1995) and Cornes and Sandler (1996). Chander and Tulkens (1995, 1997, 2009), Finus und Rundshagen (2006) and Wiesmeth (2012, pp. 108-117) apply the core concept more specifically to international environmental externalities and international public goods.
} 
Weisbach, 2010, and IPCC, 2014). So notions of equity and fair burden sharing are constant topics in negotiations about global climate change policy.

Against this background the objective of this paper is to analyse the relationship between equitable burden sharing and core stability. To this end, we focus on a specific interpretation of equity, based on Moulin's (1987) famous egalitarian-equivalence concept. We make use of the Moulin sacrifices to measure the burden which a public good contribution entails for a country, given its income and preferences. Taking these determinants of a country's burden into account also shows that burden sharing according to Moulin sacrifices is closely related to both the ability-to-pay principle and the benefit principle (see Buchholz and Peters, 2008). For a long time, both principles have played an important role in the theory of equitable public good provision (see already Wicksell, 1896, and Lindahl, 1919) and are meanwhile also taken as relevant for distributional issues in global climate policy (see, e.g., Sandler, 2004, and Pearson, 2011).

More specifically, we show that if a Pareto-optimal allocation is not in the core, it can be blocked by a group of countries with the highest Moulin sacrifices. In this sense, it is the 'overburdening' and thus somewhat 'unfair' treatment of some countries that provides the reason for core instability. By contrast, a Pareto-efficient allocation is in the core if the public good contributions are fairly equally distributed across countries according to their Moulin sacrifices. The implications of these results for international cooperation over public goods are straightforward: An equitable burden-sharing arrangement based on Moulin sacrifices can pave the way for the formation of a stable grand coalition which agrees on a Pareto-efficient allocation. In this sense, efficiency and equity issues are clearly linked.

Moulin's (1987, p. 964) seminal work maintains that the core may serve as "a meaningful guideline in the search for equitable cost sharing", since it "means that no coalition should be charged more than its 'stand alone' cost." But the explanation of this issue remains rather cursory and no explicit reference to equity criteria is made. In our paper, we clarify the relationship between the concepts of core stability, efficiency and equity, thus shedding some new light on Moulin's egalitarian-equivalent approach.

Our analysis provides an alternative to the link between equity and core stability suggested by Mas-Colell and Silvestre (1989) and Weber and Wiesmeth (1991). In the vein of Foley (1970), they show that the core of a public good economy is equivalent to the set of 'cost-share equilibria' in which utility-maximising agents-similarly as in the Lindahl model-voluntarily accept a Paretooptimal allocation when personalised cost-share functions (as a generalisation of the Lindahl 
prices) are given. In a certain sense, these cost share equilibria lead to a balanced distribution of the costs of public good supply. This approach, however, is different from ours, since our analysis is explicitly based on a specific equity norm. ${ }^{3}$

In most other papers on stability and coalition formation in an environmental context (see, e.g., Carraro and Siniscalo, 1993, Barrett, 1994, and Finus, 2001), it is assumed that the coalition members maximise the aggregate welfare of the coalition. Distributional issues within the coalition are mostly ignored, particularly as countries are usually assumed to be identical in every respect. Moreover, these papers apply very different stability concepts and-when analysing 'internal stability' - focus on the incentives for individual countries to leave a coalition. By contrast, we examine what type of contribution scheme is actually consistent with a stable grand coalition when countries are heterogeneous in preferences and income and can leave the grand coalition as a group (where this grand coalition can stand for an international environmental agreement between all countries).

We proceed as follows: Section 2 presents our framework and some preliminary considerations. In Section 3, we analyse the relationship between the core property of an efficient allocation and the distribution of Moulin sacrifices across countries. A simple example illustrates the general results and highlights some potential implications of our analysis in Section 4. In Section 5, we discuss the political relevance of our findings and the implications of an alternative technological assumption. Section 6 summarises this paper and concludes with some final remarks.

\section{A Public-Good Economy and the Moulin Sacrifice}

\subsection{The Framework}

We consider a public good economy consisting of $n \geq 2$ countries (see Bergstrom, Blume and Varian, 1986, and Cornes and Sandler, 1996, as classical references). Each country $i \in N=$ $\{1, \ldots, n\}$ is endowed with $y_{i}$ units of a private numeraire good. We denote private consumption in country $i$ by $x_{i}$ and the level of public good supply by $G$. Preferences of any country $i \in N$ are given by its utility function $u_{i}\left(x_{i}, G\right)$, which is assumed to be defined for all $\left(x_{i}, G\right)$ with $x_{i} \geq 0$ and $G \geq 0$ and to have the standard properties; i.e. it is twice continuously differentiable, strictly monotone increasing in both arguments, and strictly quasi-concave. Furthermore, we suppose

\footnotetext{
${ }^{3}$ In a framework with transferable utility and based on different normative criteria, LeBreton et al. (2013) also consider the relationship between core stability ("secession proofness") and fairness. See also Allouch (2010) for a further characterisation of core allocations in the presence of warm glow effects.
} 
that indifference curves do not intersect the $x_{i}$-axis. This additional assumption facilitates the exposition in the general case, and is also fulfilled by the Cobb-Douglas utility function, which we will use in our illustrative example later on.

The following assumption characterises how units of the private numeraire good can be transformed into units of the public good.

Technological Assumption T1: The costs of providing some amount of the public good $G \geq 0$ are given by the cost function $C(G)$, which is twice differentiable and has $C(0)=0, C^{\prime}(G)>0$, and $C^{\prime \prime}(G) \geq 0$.

Under assumption T1, an allocation $A=\left(\left(x_{i}^{A}\right)_{i \in N}, G^{A}\right)$ is feasible if $C\left(G^{A}\right) \leq \sum_{i=1}^{n} z_{i}^{A}$, where $z_{i}^{A}=y_{i}-x_{i}^{A}$ denote country $i^{\prime}$ 's expenses for the public good. If resources are not wasted so that the constraint is binding, this feasibility condition becomes $C\left(G^{A}\right)+\sum_{i=1}^{n} x_{i}^{A}=Y:=\sum_{i=1}^{n} y_{i}$. In the same vein, we say that some group of countries $K \subseteq N$ can produce a standalone allocation $A=\left(\left(x_{i}^{A(K)}\right)_{i \in K}, G^{A(K)}\right)$ in which no outsider is contributing to the public good if $C\left(G^{A(K)}\right) \leq \sum_{i \in K} z_{i}^{A(K)}$ holds and thus the condition

$$
C\left(G^{A(K)}\right)+\sum_{i \in K} x_{i}^{A(K)}=Y_{K}:=\sum_{i \in K} y_{i}
$$

is satisfied. Condition (1) trivially includes the cases in which $K$ is a singleton or $K$ comprises all countries as the 'grand coalition', simply by letting $Y_{K}=y_{i}$ or $Y_{K}=Y$. This feasibility condition allows for $z_{i}^{A}<0$, or equivalently $x_{i}^{A(K)}>y_{i}$, to hold for some country $i \in K$, which means that in allocation $A(K)$ country $i$ receives a transfer of the numeraire good from the other countries.

If, as it is fairly standard in the theory of public goods, the cost function $C(G)$ is linear so that, without loss of generality, $C(G)=G$ can be assumed, condition (1) boils down to $G^{A(K)}+$ $\sum_{i \in K} x_{i}^{A(K)}=Y$.

The feasible allocations can be completely represented by their levels of private consumption, i.e. by $\left(x_{i}^{A(K)}\right)_{i \in K}$, since the public good level $G^{A(K)}$ is then implicitly defined by the feasibility constraint. This representation will be used in the following. 
While our main results will be based on T1, we will argue in Section 5.2 that our key messages remain intact under a more general technology assumption, allowing for country-specific public production functions.

\subsection{Some Preliminary Considerations}

As a starting point, we consider feasible allocations $A=A(N)=\left(x_{i}^{A}\right)_{i \in N}$ which are also Paretooptimal and can thus be thought as the outcome of full cooperation between all $n$ countries. An allocation $A$ is Pareto-optimal if there is no other feasible allocation which gives all countries $i=1, \ldots, n$ at least the utility level $u_{i}^{A}=u_{i}\left(x_{i}^{A}, G^{A}\right)$ and at least one country $j$ a utility level exceeding $u_{i}^{A}$. As usual, these Pareto-optimal allocations can be characterised by the Samuelson condition, which in our framework reads $\sum_{i=1}^{n} \operatorname{mrs}_{i}\left(x_{i}^{A}, G^{A}\right)=C^{\prime}\left(G^{A}\right)$, where $\operatorname{mrs}_{i}\left(x_{i}^{A}, G^{A}\right)=$ $\frac{\partial u_{i} / \partial G}{\partial u_{i} / \partial x_{i}}\left(x_{i}^{A}, G^{A}\right)$ denotes country $i^{\prime}$ s marginal rate of substitution between the public and the private good at point $\left(x_{i}^{A}, G^{A}\right)$. For such Pareto-optimal allocations, the following definition states the criterion for core stability.

Definition 1: A subgroup of countries, i.e. a coalition $K \subset N$ of $k<n$ countries, can block a given Pareto-optimal allocation $A$ if there exists a blocking standalone allocation $B(K)=\left(x_{i}^{B(K)}\right)_{i \in K}$ which is feasible for coalition $K$ and satisfies

$$
u_{i}^{B(K)}=u_{i}\left(x_{i}^{B(K)}, G^{B(K)}\right)>u_{i}^{A}
$$

for all countries $i \in K$. A Pareto-optimal allocation $A=\left(x_{i}^{A}\right)_{i \in N}$ lies in the core if no coalition exists that is able to block allocation $A$.

This definition says that a blocking coalition $K$ must be able to obtain a strict Paretoimprovement for its members by abandoning the allocation $A$ and providing the public good only with its own endowments, i.e. the blocking coalition operates under the assumption that the non-members do not make a positive contribution to the public good. We will relate this specific core property to other core concepts appearing in the literature in Section 5.1. If an initial allocation were not Pareto-optimal, the group of all countries, i.e. the grand coalition, could trivially 
block such an allocation in accordance with Definition 1. To exclude this uninteresting case, the definition is restricted to Pareto-optimal allocations.

To characterise the core of a public good economy more precisely, and to link the core property to concepts of equity, we will make use of the egalitarian-equivalent public good levels as devised by Moulin (1987), which are defined as follows.

Definition 2: Given some feasible (and not necessarily Pareto-optimal) allocation $A=\left(x_{i}^{A}\right)_{i \in N}$ with public good supply $G^{A}$, country $i^{\prime}$ 's egalitarian-equivalent level of public good supply $\bar{G}_{i}^{A}$ is implicitly defined by the condition

$$
u_{i}\left(y_{i}, \bar{G}_{i}^{A}\right)=u_{i}\left(x_{i}^{A}, G^{A}\right)=u_{i}^{A} .
$$

The Moulin sacrifice of country $i$ is then

$$
s_{i}^{A}:=G^{A}-\bar{G}_{i}^{A} .
$$

The definition of the egalitarian-equivalent public good level means that country $i$ is indifferent between the original allocation $A$ and a hypothetical allocation $B$ in which it consumes $\bar{G}_{i}^{A}$ of the public good and $y_{i}$ of the private good. In this hypothetical allocation, country $i$ makes no contribution to the public good, converts all of its endowment into private consumption, and receives just enough of the public good to obtain the same utility level as in the original allocation (see Figure 1). Under our assumptions on the utility functions, egalitarian-equivalent public good levels exist and are uniquely determined for all countries if public good supply $G^{A}$ and all private consumption levels $x_{i}^{A}$ are strictly positive.

Figure 1 depicts the indifference curve corresponding to the utility level $u_{i}^{A}$, with $x_{i}$ on the horizontal and $G$ on the vertical axis. The function $h_{i}^{A}(G)=h_{i}\left(G, u_{i}^{A}\right)$ captures this indifference curve as a function of public good supply $G$, relating the level of private consumption that country $i$ needs to attain utility $u_{i}^{A}$ with any level of public good provision $G$.

The Moulin sacrifice of country $i$ is a willingness-to-pay measure. It shows that, starting from the public good level $\bar{G}_{i}^{A}$ and zero public good contribution of country $i$ (see point $B$ in Figure 1), country $i$ is ready to donate $z_{i}^{A}=y_{i}-x_{i}^{A}$ to increase public good supply from $\bar{G}_{i}^{A}$ to $G^{A}$. Con- 
versely, starting from the initial allocation $A$ (see point $A$ in Figure 1), country 1 is willing to give up $s_{i}^{A}$ of its public good consumption to avoid any contribution to the public good and thus to raise its private consumption from $x_{i}^{A}$ to $y_{i}$. In this sense, the Moulin sacrifice can be interpreted as country $i$ 's burden of contributing to the public good, expressed not in units of the private but in units of the public good.

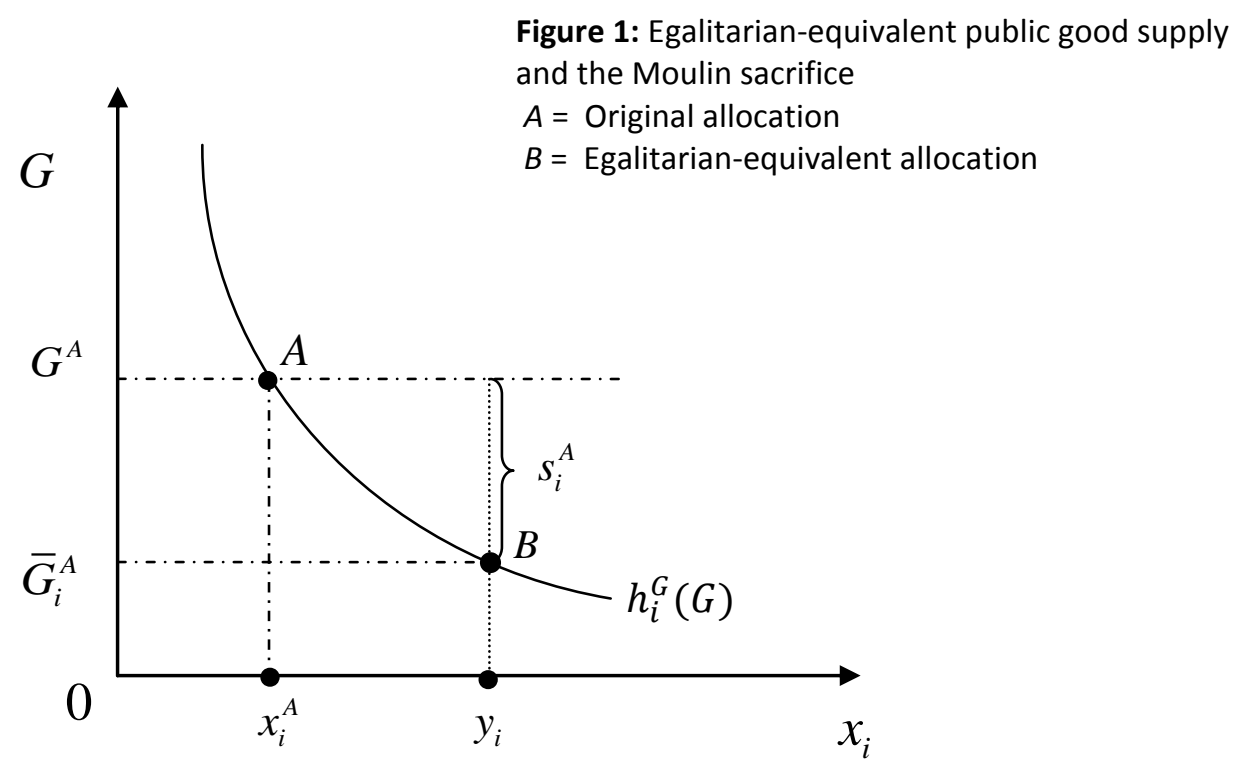

The size of the Moulin sacrifices depends on the level of public good contributions, the countries' preferences for the public good and their income levels in the following way (see Buchholz and Peters, 2008, for details and the Cobb-Douglas example in Section 4 of this paper as an illustration):

- If all countries have the same income levels and the same preferences, then their Moulin sacrifices in a given allocation are positively correlated with their levels of public good contributions.

- If all countries make the same public good contribution, their Moulin sacrifices in a given allocation are negatively correlated with the strength of their preferences for the public good and, given normality, with their income levels. In this way, the concept of the Moulin sacrifice reflects both the benefit principle and the ability-to-pay principle: A country's burden of public good provision as measured by its Moulin sacrifice is lower when this 
country benefits more from the public good (benefit principle) and when it is richer and can thus afford to pay more for the public good (ability-to-pay principle). ${ }^{4}$

In the following section, the Moulin sacrifice will be used as an equity standard by which the core property can be characterised.

\section{Equity and the Stability of Coalitions}

First of all, we provide a basic condition that is necessary and sufficient for the existence of a coalition $K$ able to block an allocation $A$.

Lemma: Under assumption T1, coalition $K$ can block a Pareto-optimal allocation $A$ if and only if there is some public good level $\tilde{G}<G^{A}$ such that

$$
Y_{K}^{A}(\tilde{G})=\sum_{i \in K} h_{i}^{A}(\tilde{G})+C(\tilde{G})<Y_{K}
$$

Any $\tilde{G}$ which fulfils condition (5) can be the public good supply in a blocking allocation chosen by coalition $K$.

\section{Proof: See Appendix A 1.}

Given a Pareto-optimal allocation $A$ and a coalition $K$, the function $Y_{K}^{A}(G)$ shows the total income which coalition $K$ needs to supply the public good level $G$ and, at the same time, to ensure that all coalition members attain the same utility level as in allocation $A$. If we further define $\hat{Y}_{K}^{A}:=\min \left\{Y_{K}^{A}(G): G>0\right\}$, then condition (5) means that coalition $K$ can block allocation $A$ if and only if the total endowment $Y_{K}$ of the coalition exceeds the critical level $\hat{Y}_{K}^{A}$. Thus, in applying duality theory (see, e.g., Cornes, 1992), we can provide both a necessary and sufficient criterion for the ability of a coalition to block a given allocation.

Based on the Lemma, we can now show that, if blocking is possible at all, there always exists a specific type of a blocking coalition.

\footnotetext{
${ }^{4}$ The relationship between willingness-to-pay on the one hand and both the benefit principle and the ability-to-pay principle on the other hand is also discussed in a non-technical way by Pearson (2011, pp. 174-175).
} 
Proposition 1: Assume that some coalition $K$ can block a Pareto-optimal allocation $A=\left(x_{i}^{A}\right)_{i \in N}$, i.e. this allocation is not in the core. Then there exists some threshold level $\breve{s}$ for the Moulin sacrifices such that $\breve{K}=\left\{i \in N: s_{i}^{A} \geq \breve{s}\right\}$ is a blocking coalition too.

Proof: See Appendix A 2.

The construction underlying the proof of Proposition 1 can be explained as follows. We start from some coalition $K$ that blocks allocation $A$ and provides $G^{B(K)}<G^{A}$ units of the public good. Then another blocking coalition $K^{\prime}$ is obtained in two steps. First, we eliminate from the blocking coalition all countries $j \in K$ which can attain the utility level $u_{j}^{A}$ only if they receive a positive income transfer and thus make a negative contribution to the public good in the original blocking allocation with public good supply $G^{B(K)}$. Second, we add to the blocking coalition all countries $l \in N / K$ that attain their utility level $u_{j}^{A}$ by making a non-negative contribution to the public good supply $G^{B(K)}$ in the blocking allocation.

The positions of an expelled country $j$ and a newly included country $l$ are visualised in the left and the right panel of Figure 2. Given public good supply $G^{B(K)}$ of the initial blocking coalition $B(K)$, the values $h_{j}^{A}\left(G^{B(K)}\right)$ and $h_{l}^{A}\left(G^{B(K)}\right)$ define the private consumption levels through which countries $j$ and $l$ attain $u_{j}^{A}$ and $u_{l}^{A}$, which are the minimum levels needed to make these countries members of a blocking coalition. In the case of an expelled country $l$, the private consumption level $h_{j}^{A}\left(G^{B(K)}\right)$ exceeds its initial endowment $y_{j}$, which entails a negative public good contribution by country $j$ and a low Moulin sacrifice $s_{i}^{A}<\breve{s}:=G^{A}-G^{B(K)}$ (see the left panel of Figure 2). By contrast, in the case of an included country $l$, the private consumption level $h_{l}^{A}\left(G^{B(K)}\right)$ falls below $y_{l}$, such that this country makes a positive public good contribution and has a high Moulin sacrifice $s_{i}^{A}>\breve{s}$ (see the right panel of Figure 2). Thus countries with a low Moulin sacrifice drop out of the blocking coalition while countries with a high Moulin sacrifice enter the blocking coalition.

This systematic procedure of shrinking and enlarging the blocking coalition leaves the countries that have the highest Moulin sacrifices in the original allocation $A$ as members of a newly formed blocking coalition. 


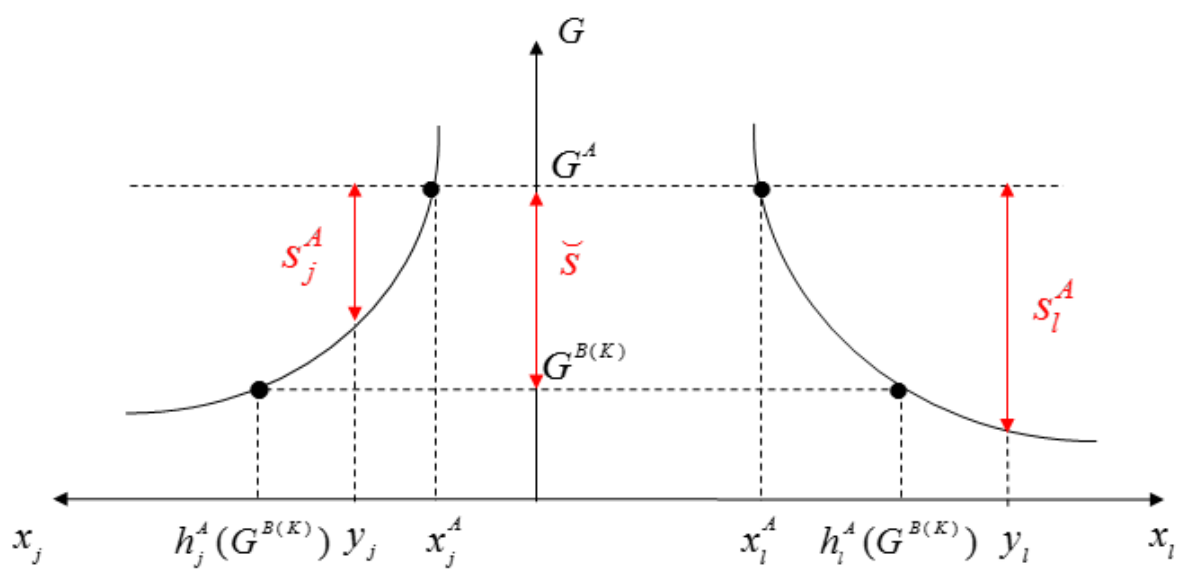

Proposition 1 provides a normatively oriented explanation as to why a group of countries may have a reason to deviate from an international agreement (e.g. an international environmental agreement) and break up the grand coalition: As measured by their Moulin sacrifices, the members of this group are 'overburdened' in the original allocation. They make particularly high sacrifices for public good provision, thus violating a specific notion of equity. By forming a blocking coalition, the originally disadvantaged countries get rid of countries which took a free-ride on the 'too high' public good contribution of the separating countries.

As explained at the end of Section 2, the Moulin sacrifice of a country increases with its contribution to the public good and decreases with its income level and its preference intensity for the public good. Thus, the natural candidates for a blocking coalition are those countries which make a high contribution to the public good in the initial, Pareto-optimal allocation and, at the same time, are relatively poor or exhibit weak preferences for the public good. Regarding these countries the benefit principle or the ability-to-pay principle is violated. From the viewpoint of our analysis, it is the violation of these two principles which explains the incentive to break off from a coalition and thus causes the instability of non-core allocations.

Referring to the inequality of Moulin sacrifices across countries, Proposition 1 suggests that core stability is to be expected if the Moulin sacrifices of the countries are homogenous. To explore this notion in detail, let $E=\left(x_{i}^{E}\right)_{i \in N}$ denote the Pareto-optimal allocation for which $s_{i}^{E}=: s^{E}$ holds for each $i=1, \ldots, n$, i.e. in which the size of the Moulin sacrifice is the same for 
each country. Such an equal-Moulin-sacrifice (EMS) solution with public good supply $G^{E}$ exists and is unique (see Buchholz and Peters, 2008). In the allocation $E$, the contributions of countries with high income or strong preferences for the public good are high while those of countries with low income or weak preferences for the public good are small. We can now prove the following result, which shows that any Pareto-optimal allocation whose corresponding Moulin sacrifices lie in the neighbourhood of the EMS allocation is in the core.

Proposition 2: Let income levels and preferences of all countries be given. Then there exists some $\varepsilon>0$ so that all Pareto-optimal allocations $A$ with Moulin sacrifices $s_{i}^{A} \in\left[s^{E}-\varepsilon, s^{E}+\varepsilon\right]$ for all $i=1, \ldots, n$ lie in the core.

Proof: See Appendix A 3.

According to Proposition 2, the grand coalition which agrees on a Pareto-optimal allocation is stable if the burden of public good provision-as measured by the Moulin sacrifices-is not too unevenly shared across countries. This conclusion not only extends a result in Moulin (1987), ${ }^{5}$ but it also gives the core concept a meaningful interpretation by relating the core concept to a particular normative criterion of an equitable burden-sharing arrangement which-as discussed above-encompasses both the ability-to-pay and the benefit principle.

By making an additional assumption on the countries' preferences, we can establish a converse to Proposition 2, which says that any coalition will be able to block a Pareto-optimal allocation if the Moulin sacrifices of all coalition members sufficiently differ from the level of the equal Moulin sacrifices in allocation $E$.

CEP Preferences: The preferences of country $i \in N$ can be represented by a utility function of the form $u_{i}\left(x_{i}, G\right)=\psi(G) x_{i}+\varphi_{i}(G)$.

\footnotetext{
${ }^{5}$ In contrast to Moulin's (1987) result, Hahn and Gilles (1998) provide an example of an egalitarian-equivalent allocation that does not lie in the core in a two-agent public good economy. Hahn and Gilles' (1998) framework, however, differs from the standard public good model in several respects. So, as the agents can jointly carry out only one public project, they face a discrete and not a continuous choice of public good supply-a fact that Hahn and Gilles (1998) identify as the main reason why they reach a conclusion being different from Moulin (1987). More importantly, Hahn and Gilles (1998) also assume in their example that joint provision of the public project by the two agents makes one agent worse off than in her standalone solution. Without this rather unorthodox assumption, the egalitarianequivalent allocation would also be in the core of the Hahn and Gilles' (1998) example.
} 
For $\psi(G)=1$, the CEP assumption generalises the case in which all countries have quasilinear utility functions by allowing for a country-specific valuation of the public good $\varphi_{i}(G)$. Furthermore, the CEP assumption is also fulfilled if all countries have the same Cobb-Douglas utility function, i.e. if $\psi(G)=G^{\alpha}$ and $\varphi_{i}(G)=0$.

It is well-known from the literature on public goods that public good supply will be the same in all Pareto-optimal allocations if and only if the CEP assumption is satisfied (Bergstrom and Cornes, 1983). In particular, that means the efficient level of public good provision is independent of the distribution of private consumption and thus utility among countries. Given CEP preferences, we then obtain the following result:

Proposition 3: Assume CEP preferences and let some group of countries $K \subset N$ be given. Then there exists a threshold level $\underline{s}(K)>s^{E}$ for Moulin sacrifices such that coalition $K$ can block a Pareto-optimal allocation $A$ if $s_{i}^{A}>\underline{s}(K)$ is satisfied for all $i \in K$.

Proof: See Appendix A 4.

If the Moulin sacrifices of all members of a potential coalition are sufficiently high in the initial allocation (i.e. if the sacrifices exceed the threshold level $\underline{s}(K)$ ), then this subgroup of countries can indeed be better off outside of the 'grand' coalition. This result confirms the suggestion that asymmetric burden sharing enables subgroups of countries to block Pareto-optimal solutions. Conversely, Proposition 2 shows that equitable burden sharing prevents Pareto-optimal allocations from being blocked.

The next Proposition, which holds without invoking the CEP assumption, reinforces this notion from a somewhat different position. It shows that, if we start from a setting with heterogeneous Moulin sacrifices, equalising the Moulin sacrifices through an income transfer will keep a given Pareto-optimal allocation in the core. Thus, redistribution of income which leads to a more equal burden sharing can never destabilise cooperative agreements.

Proposition 4: Suppose that some Pareto-optimal allocation $A$ is in the core for some initial distribution of endowments $\left(y_{1}, \ldots, y_{n}\right)$. This allocation will remain in the core if the endowment of a country with a high Moulin sacrifice is decreased by some amount and the endowment of an- 
other country with a lower Moulin sacrifice is increased by the same amount without changing the ranking of the sacrifice levels.

Proof: See Appendix A 5.

The intuition behind Proposition 4 is straightforward. For a fixed allocation $A$, a decline in the endowment of a country translates one-by-one into a lower contribution of this country to the public good provision, and thus causes a fall in its Moulin sacrifice. Conversely, a larger endowment raises the contribution of a country to the public good and thus its Moulin sacrifice. This way, the distribution of the Moulin sacrifices becomes more homogenous as long as their ranking is preserved, which stabilises the Pareto-optimal allocation $A$.

\section{A Cobb-Douglas Example}

To illustrate our results, we now consider the special case in which the Cobb-Douglas utility function $u_{i}\left(x_{i}, G\right)=x_{i} G^{\alpha_{i}}$ represents the preferences of any country $i=1, \ldots, n$. Countries may differ in both their income $y_{i}$ and their preference parameter $\alpha_{i}$ so that this example enables us to highlight the importance of asymmetries across countries for international cooperation. A higher value of $\alpha_{i}$ indicates a stronger preference for the public good, since the marginal rate of substitution $\operatorname{mrs}_{i}\left(x_{i}^{A}, G^{A}\right)=\alpha_{i} x_{i} / G$ between the public and the private good (and thus the marginal utility of the public good in relation to that of the private good) increases with $\alpha_{i}$ at any point $\left(x_{i}^{A}, G\right)$.

In the Cobb-Douglas case, the egalitarian-equivalent level of public good supply is given by $\bar{G}_{i}^{A}=\left(x_{i}^{A} / y_{i}\right)^{1 / \alpha_{i}} G^{A}$. Using Definition 2, the Moulin sacrifice of country $i$ then becomes

$$
s_{i}^{A}=\left[1-\left(\frac{x_{i}^{A}}{y_{i}}\right)^{\frac{1}{\alpha_{i}}}\right] G^{A} .
$$

This formula reveals that, in an equal-Moulin-sacrifice solution $E=\left(x_{i}^{E}\right)_{i \in N}$, the condition 


$$
\frac{x_{i}^{E}}{y_{i}}=\gamma^{\alpha_{i}}
$$

is satisfied for some constant $\gamma<1$ for all countries.

Condition (7) characterises a fair burden sharing agreement according to the Moulin criterion. First of all, it implies that each country contributes to the public good provision, i.e. complete free-riding is not possible, since $\gamma<1$ implies that private consumption of each country falls short of its income, i.e. $x_{i}^{E}<y_{i}$.

For a further interpretation of (7), we initially assume that the Cobb-Douglas preferences are identical for all countries, i.e. that all $\alpha^{\prime}$ s take the same value so that the CEP assumption is satisfied. Then it directly follows from (7) that each country pays the same proportion of its national income for the public good in the EMS solution. As in the theory of fair taxation, such a cost sharing arrangement can be interpreted as a special version of the ability-to-pay principle. In particular, it implies that rich countries contribute more in absolute terms to the public good than poor countries.

If the preferences of the countries, however, differ in the parameter $\alpha_{i}$, then the country with a stronger preference for the public good will spend a higher share of its income for the public good than a country with a weaker preference. This cost sharing according to preference intensity follows from condition (7), since $\gamma^{\alpha_{i}}$ is a decreasing function of $\alpha_{i}$ for $\gamma<1$, and clearly reflects the benefit principle.

For a further discussion of the Cobb-Douglas example, let the production technology of the public good be linear, with $C(G)=G$. As a first step, we consider the two-country case in which the preferences of both countries are identical with $\alpha_{1}=\alpha_{2}=1$, but their incomes may differ with $y_{1}+y_{2}=1$. Then the lower (upper) contour of the core set is given by $x_{1}^{A}=(1 / 2) y_{1}^{2}$ $\left(x_{1}^{A}=y_{1}-(1 / 2) y_{1}^{2}\right)$, which describes the consumption bundles that leave country 1 (country 2) indifferent between staying in the coalition, which gives utility $x_{i}^{A} / 2$, and choosing the standalone allocation, which gives utility $y_{i}^{2} / 4$. The lower and upper contours meet in the origin $O$ and point $M=(1,1 / 2)$ and enclose the core lens, as the solid lines in Figure 3 illustrate. The higher the income of a country, the higher its consumption needs to be to keep the country in the coalition, so that the lower and higher contours are upward sloping. 


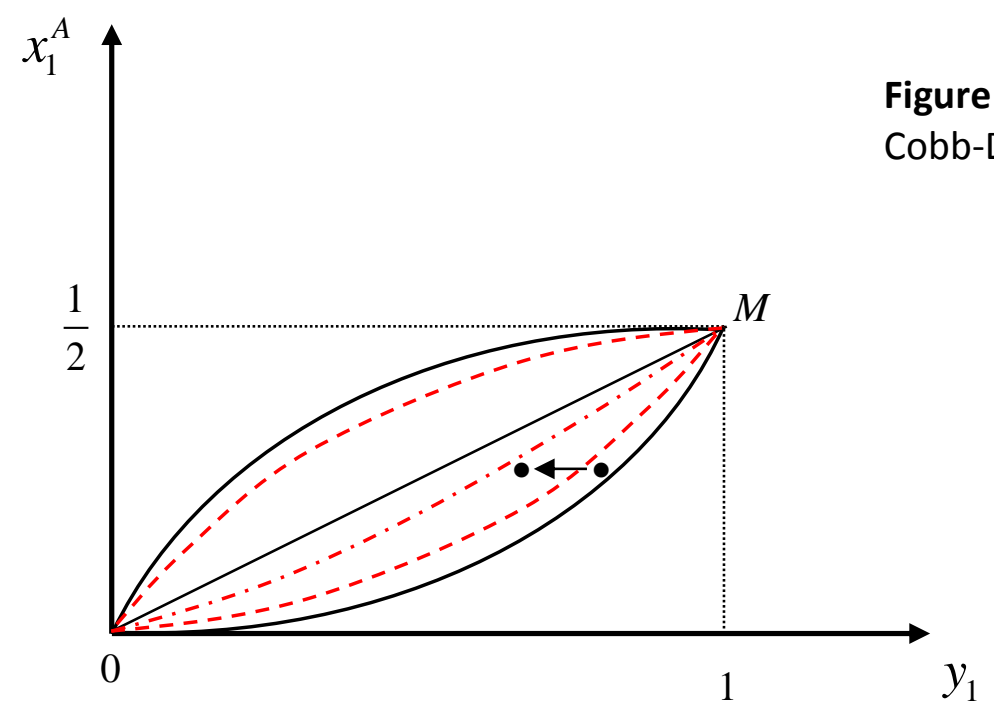

The Moulin sacrifices of the two countries will be equalised if $x_{1}=(1 / 2) y_{1}$. This condition yields the straight equal-Moulin-sacrifice (EMS) line from the origin $O$ to point $M$, along which the Moulin sacrifices of both countries are $s^{E}$, and which lies within the core lens. Below (above) the EMS line, the Moulin sacrifice of country 1 is larger (smaller) than that of country 2. If the Moulin sacrifices of country $i$ is below (above) the threshold level $(1 / 2)\left[1-\left(y_{i} / 2\right)\right]$, the corresponding allocation will be sufficiently close to (far from) the EMS line, and will thus lie inside (outside) the core lens. This confirms Proposition 2 and, as the CEP assumption holds for identical CobbDouglas preferences, also Proposition 3. Figure 2 additionally illustrates Proposition 4: Consider the allocation indicated by the dot in the core lens. Any horizontal shift of this dot towards (but not beyond) the EMS line captures a redistribution of endowment such that the new allocation is also in the core.

In a second step, we now consider the case of asymmetric preferences and assume that $\alpha_{1}=1$ and $\alpha_{2}=1 / 8$, i.e. that country 2 now has much weaker preferences for the public good than country 1. In Figure 3, the broken lines depict the core lens and the EMS line for this case. (Details of the calculation can be obtained from the authors on request.)

The location of these lines is very intuitive. Compared to the case with symmetric preferences, the core lens shrinks for two reasons: First, the minimum consumption level that is required to keep country 1 in the coalition has to increase to compensate country 1 for the smaller level of the coalition's public good provision, which is caused by country 2's weaker preferences for the public good. This explains the upward shift of the lower contour of the core lens. Second, country 2 requires a higher minimum level of private consumption in the cooperative solution, as its 
weaker preferences for the public good entail that it finds contributing to the public good less attractive. This explains the downward shift of the upper contour line.

The EMS line also moves downwards, as depicted by the broken line below the straight OM line. Since country 1 has now stronger preferences for the public good than country 2, country 1 needs to contribute more than a proportional share of its income to the public good to ensure that the Moulin sacrifice is the same for the two countries. Obviously, the EMS line is again in the core, as Proposition 2 implies, and thus meets the other lines in points $O$ and $M$.

Finally, we introduce a third country and assume that $\alpha_{1}=1, \alpha_{2}=\alpha_{3}=1 / 8, y_{1}=y_{2}=2 / 5$ and $y_{3}=1 / 5$. That is, country 1 and country 2 are equally rich but country 2 has weaker preferences for the public good than country 1 , while country 3 is poorer than the other countries and has the same weak preferences for the public good as country 2. To further illustrate the relationship between blocking coalitions and the size of the Moulin sacrifices, we specifically consider the Pareto-optimal allocation $A$ in which all countries contribute the same share of their initial endowment to the public good. Such a proportional funding leads to $A=\left(x_{1}^{A}, x_{2}^{A}, x_{3}^{A}\right)=$ $(16 / 59,16 / 59,8 / 59)$ and $G_{A}=19 / 59$. As a short calculation shows, country 2 enjoys a higher utility level with its standalone allocation $x_{2}^{B(\{2\})}=16 / 45$ and $G^{B(\{2\})}=2 / 45$ and can thus block the Pareto-optimal allocation A. Proposition 1 states that, under these circumstances, all countries whose Moulin sacrifices exceed some threshold level are also able to block the initial allocation $A$. Using the definition given in the proof of Proposition 1, this critical threshold is $\breve{s}=G^{A}-G^{B(\{2\})}=19 / 59-2 / 45=0.278$. In allocation $A$, the Moulin sacrifice of both country 2 and country 3 is 0.308 and thus exceeds this critical value, while that of country 1 is only 0.104 . Consequently, the sub-coalition consisting of countries 2 and 3 is also able to block the allocation $A$, e.g. by choosing the allocation $B(\{2,3\})=\left(x_{2}^{B(\{2,3\})}, x_{3}^{B(\{2,3\})}\right)=(16 / 45,8 / 45)$ with $G^{B(\{2,3\})}=3 / 45$.

This example also gives some clues about successful coalition formation strategies. While countries 2 and 3 can jointly block the initial Pareto-efficient allocation, only country 2 can do so on its own. To prevent a blocking coalition, it is sufficient that country 1 'bribes' country 2 , offering, for instance, a 'discount' on country 2's contributions to the public good. In this way, country 1 cannot only prevent country 2 from blocking a Pareto-efficient allocation on its own, but also from joining forces with country 3 . Thus, country 1 can stabilise the grand coalition by making concessions to country 2 only, and without compromising with country 3 (but not vice versa). 


\section{Discussion}

\subsection{Political Relevance and Implications}

The core property of a public good allocation as defined above rests on a simple assumption on the behaviour of countries outside a blocking coalition. We suppose that the public good contributions of the countries left behind are zero, which, from the perspective of the coalition, is the worst possible response of the countries outside the coalition. Making this behavioural assumption, our notion of the core property corresponds to both the $\alpha$-core concept and $\beta$-core concept.

More realistic, however, is the assumption that the countries outside the coalition exhibit Nash behaviour and independently choose their best responses to the public good contributions of the coalition. This alternative assumption leads us to the concept of the $\gamma$-core as suggested by Chander and Tulkens $(1995,1997)$. But if public good supply of the deviating coalition is large enough, the optimal response of the outsiders will be a contribution of zero to the public good. Hence, all three core concepts coincide in this case.

The incentive for a coalition to break off would be stronger if the public good contributions of the outsiders were positive instead of zero (see, e.g., Kolm, 2006, for a further discussion of this issue). Thus, in our framework, any Pareto-optimal allocation that is not in the $\alpha$-core or the $\beta$ core can never be in the $\gamma$-core. If-due to an unequal burden sharing according to the Moulin sacrifices - an allocation does not satisfy the core criterion of Definition 1, the cooperative arrangement will not be stable according to all three core concepts. This relationship links the analysis in our paper to the $\gamma$-core and thus further motivates "the relevance of the core to political reality" (Foley, 1970, p. 72).

From a practical perspective, our analysis suggests some rule-of-the-thumb criteria for successful global cooperation in the spirit of a "common but differentiated responsibility." Fundamentally, success in international cooperation requires a burden sharing such that the Moulin sacrifices are fairly equal across countries. In this sense, there is a common responsibility. However, similar Moulin sacrifices can imply very different levels of contribution to a public good. In this sense, there is a differentiated responsibility, which reflects the ability-to-pay and the benefit principle.

For a very rough treatment of the policy implications, consider the case of international climate policy and assume that there are three groups of countries: Group 1 (EU) with high income and strong preferences for climate protection; group 2 (USA, Canada, Australia) also with high 
income but weak preference for the public good; group 3 (Brazil, China and India as big emerging economies) with low income and also weak preferences for climate protection. Under these circumstances, our results suggest that group 1 should spend more on climate protection than group 2, which in turn should spend more than group 3. Otherwise, groups 2 and 3 , separately or jointly, can block a global climate agreement, since the ability-to-pay-principle (in the case of group 3) or the benefit principle (in the case of group 2 and 3) would be violated. Depending on the specific preferences, an EMS solution might mean that group 1 contributes more to climate protection not only in absolute terms but also expressed as share of income, as the Cobb-Douglas example in Section 4 has shown.

The simple three-country example in Section 4 hints at how group 1 might prevent groups 2 and 3 from forming a blocking coalition, even if Moulin sacrifices cannot be equalised across all countries. In this case, 'bribing' countries such as USA and Canada might not only keep them in a grand coalition, but it could also prevent the countries of group 3 from defecting from the grand coalition, as group 3 cannot form a blocking coalition on its own.

\subsection{Technology}

The results of the previous sections are based on assumption T1; that is, all countries are supposed to operate with the same technology. However, the public good production functions may differ widely between countries, since technological capacities and, in the case of climate change, meteorological conditions for generating renewable energy vary significantly across the globe. These features can be taken into account through an alternative technological assumption.

Technological Assumption T2: Each country $i \in N$ has a country-specific public good production function $g_{i}\left(z_{i}\right)$, with $g_{i}(0)=0, g_{i}^{\prime}\left(z_{i}\right)>0$ and $g_{i}^{\prime \prime}\left(z_{i}\right) \geq 0$, where $z_{i} \geq 0$ is the amount of the numeraire good that is used for public good provision in country $i$.

Under assumption T2, an allocation $\left(x_{i}^{A}\right)_{i \in N}$ with public good supply $G^{A}$ is then feasible if $G^{A}=\sum_{i=1}^{n} g\left(z_{i}^{A}\right)$ and $\sum_{i=1}^{n}\left(x_{i}^{A}+z_{i}^{A}\right)=Y$. The total costs of public good provision in terms of private consumption now depends on which country produces how much of the public good.

In the scenario with $\mathrm{T} 2$, we assume that a coalition $K \subseteq N$ minimises its total expenditure necessary to produce some amount $G$ of the public good. That is, for any public good level $G$, the group of cooperating countries solves the optimisation problem $\min \sum_{i \in K} z_{i}$ w.r.t $\sum_{i \in K} g\left(z_{i}\right)=$ 
$G$, which gives a coalition-specific cost function $C_{K}(G)$. The implementation of the optimal production plan may be accompanied by income transfers between the coalition members so that $z_{i}$ may become different from $y_{i}-x_{i}$ for countries $i \in K$. However, no transfers can take place between the non-cooperating outsiders, i.e. $z_{i}=y_{i}-x_{i} \geq 0$ holds for all $i \in N / K$. As we sketch now, our key messages will remain intact, although with some slight modifications, if we replace assumption T1 with T2.

The results of the Lemma continue to hold since, given some subgroup $K$, we can simply substitute the group-specific cost function $C_{K}$ for $C(K)$. Also, Proposition 1 remains valid if we impose the additional constraint that no member of the blocking coalition can have a private consumption level above its income in the blocking allocation. ${ }^{6}$ Without the additional constraint $x_{i}^{B(K)} \leq y_{i}$ for all $i \in K$, a successful blocking coalition might also include countries with low Moulin sacrifices in the original allocation. Such a situation can only occur if these countries receive a net transfer from the other coalition members. Intuitively, these countries with low Moulin sacrifices must be highly productive in providing the public good and can thus produce the public good at a lower cost than the other coalition members. In this case, the other coalition members face incentives to 'bribe' the high-productivity countries to participate in a blocking coalition in order to reduce the overall costs of the public good provision. These cost savings more than compensate the other coalition members for financing the transfers.

However, we can show that in this case it is still a subgroup with high Moulin sacrifices which has an incentive to initiate a blocking coalition by making 'bribing' payments. In this sense, the spirit of our conclusion remains intact. The same is true for Proposition 4. As this proposition makes use of Proposition 1, Proposition 4 remains valid under the same additional restrictions as Proposition 1. In this context, note that small income transfers do not affect the cost function $C_{K}(G)$ for any subgroup $K \subseteq N$. Finally, Proposition 2 still holds under assumption T2 without any further qualifications.

\section{Conclusion}

The main purpose of this paper is to establish a link between the stability of cooperation (and thus the possibility to attain an efficient solution) and the equity of burden sharing. Using the concepts of core stability and Moulin sacrifices, we have shown that if a Pareto-optimal alloca-

\footnotetext{
${ }^{6}$ With this modification, the second inequality of relationship (A-1) in the proof of Proposition 1 becomes redundant, as $K \subseteq K^{\prime}$. After the last inequality in (A-1), we have to set $C_{K}\left(G^{B(K)}\right) \geq C_{K^{\prime}}\left(G^{B(K)}\right)$, which is trivially satisfied.
} 
tion lies outside the core, it will be rejected by the group of countries with the highest Moulin sacrifices. These 'overburdened' countries face a particularly strong incentive to break off and standalone, which gives a novel equity based interpretation for the core property.

The relevance of a balanced distribution of Moulin sacrifices for core stability is also highlighted by the fact that a fairly equalised distribution of Moulin sacrifices ensures that the Paretooptimal allocation is in the core. Thus, a grand coalition can be maintained if the members are treated equally according to their Moulin sacrifice. This provides some guidelines for the design of an agreement that aims at full cooperation and a Pareto-optimal allocation. For instance, everything else equal, a richer country should contribute more to the public good than a poorer country, reflecting the ability-to-pay principle. Also, a country with weak preferences for the public good might only need to bear a small share of the costs of public good provision, possibly even if it is quite rich. This reflects the benefit principle.

As the Moulin sacrifice is a utility-based measure of burden, this notion of equity is different from many other concepts that are discussed in the context of international environmental negotiations on climate change, such as the concept that all countries should carry out the same relative reduction of emissions (see, e.g., Bretschger, 2013). Such non-utility based concepts of equity, however, ignore preference intensities, which are in general a crucial determinant of the behaviour of individuals and governments. Thus, they only provide a distorted picture of the welfare implications of different allocations and might not be particularly useful for achieving a successful cooperation.

Finally, the link between the core concept and the Moulin sacrifice provides an additional normative motivation for the core concept, particularly as the Moulin sacrifice incorporates both the ability-to-pay and the benefit principle. In this way, we have continued the long-standing discussion in public economics about the relationship between the stability of cooperation and the basic principles of fair burden sharing (see already Wicksell, 1896). In the current debate on climate policy, the benefit principle-unlike the ability-to-pay principle-only plays a minor role. Subsequent research on the public choice aspects of climate policy might explain this neglect and, simultaneously, show whether this may also account for the limited success of climate negotiations. 
Acknowledgements: We thank the participants of a seminar at the CAU Kiel, at the meeting of the AURÖ in Linz and the TU Berlin and particularly Thomas Eichner for their valuable comments. We in particular thank four referees whose valuable comments and suggestions have been very helpful to improve our paper. Furthermore, we acknowledge financial support from the BMBF (German Ministry of Education and Research) through RECAP 15 (FKZ 01LA1139A) and ECCUITY (FKZ 01LA1104B).

\section{Appendix}

\section{A 1: Proof of the Lemma}

(i) If: From inequality (5) in the main text, we get $d:=\sum_{i \in K}\left(y_{i}-h_{i}^{A}(\tilde{G})\right)-C(\tilde{G})>0$. Thus, the allocation $B(K)$ defined by $G^{B(K)}=\tilde{G}$ and $x_{i}^{B(K)}=h_{i}^{B(K)}(\tilde{G})+(d / k)$ for all $i \in K$ is feasible for subgroup $K$, since it fulfils condition (1) of the main text. Clearly, $B(K)$ blocks the initial allocation $A$, since all countries in subgroup $K$ are strictly better off in $B(K)$ than in allocation $A$. Because public good supply $G^{B(K)}$ in a blocking allocation being constructed in this way can be chosen as any $\widetilde{G}$ which satisfies (5), this also shows the last part of the Lemma.

(ii) Only if: If $K$ can block allocation $A$ by choosing the allocation $B(K)$ with public good supply $G^{B(K)}$, then condition (2) directly gives $h_{i}^{A}\left(G^{B(K)}\right)<x_{i}^{B(K)}$ for all $i \in K$. From equation (1) in the main text, it thus follows that condition (5) is fulfilled for $\tilde{G}=G^{B(K)}$. But if this is the case for some $\tilde{G}$, there even is a $\widetilde{G}<G^{A}$ for which inequality (5) also holds. To show this, we start from the Samuelson condition for the Pareto-optimal allocation $A$, which reads as $\sum_{i=1}^{n}\left[\partial h_{i}^{A}\left(G^{A}\right) / \partial G\right]+C^{\prime}\left(G^{A}\right)=0$. (Since $\operatorname{mrs}_{i}\left(h_{i}^{A}\left(G^{A}\right), G^{A}\right)=-\partial h_{i}^{A}\left(G^{A}\right) / \partial G$, this formulation of the Samuelson condition is equivalent to that stated at the beginning of Section 2.2.) As $\partial h_{i}^{A} / \partial G<0$ especially for all $i \notin K$, we get $\partial Y_{K}^{A}\left(G^{A}\right) / \partial G=\sum_{i \in K}\left[\partial h_{i}^{A}\left(G^{A}\right) / \partial G\right]+C^{\prime}\left(G^{A}\right)>0$. Convexity of indifference curves and $C^{\prime \prime}(G) \geq 0$ furthermore imply that $\partial Y_{K}^{A}(G) / \partial G>0$ holds also for all $G \geq G^{A}$, and thus that $Y_{K}^{A}(G)>Y_{K}^{A}\left(G^{A}\right)$ for all $G>G^{A}$. Combined with continuity of the function $Y_{K}^{A}(G)$, this entails that condition (5) can be satisfied for some $\tilde{G}<G^{A}$ as soon as it can be satisfied at all.

\section{A 2: Proof of Proposition 1}

If some coalition $K$ can block a given allocation $A$, the Lemma gives that $G^{B(K)}<G^{A}$ can be assumed for the public good supply $G^{B(K)}$ in the blocking allocation. We can then show that the 
coalition defined by $K^{\prime}:=\left\{i \in N: G^{B(K)} \geq \bar{G}_{i}^{A}\right\}$ is also able to block allocation $A$. As indifference curves are downward sloping, we clearly have $K^{\prime}:=\left\{i \in N: h_{i}^{A}\left(G^{B(K)}\right) \leq y_{i}\right\}$, which implies the following relations:

$$
\sum_{i \in K^{\prime}}\left[y_{i}-h_{i}^{A}\left(G^{B(K)}\right)\right] \geq \sum_{i \in K^{\prime} \cap K}\left[y_{i}-h_{i}^{A}\left(G^{B(K)}\right)\right] \geq \sum_{i \in K}\left[y_{i}-h_{i}^{A}\left(G^{B(K)}\right)\right]>C\left(G^{B(K)}\right) .
$$

The first inequality in (A-1) is satisfied, since $y_{i}-h_{i}^{A}\left(G^{B(K)}\right) \geq 0$ for all $i \in K^{\prime}$ follows from the definition of $K^{\prime}$, and since, clearly, $K^{\prime} \cap K \subseteq K^{\prime}$. The second inequality is obtained because, for all countries $i$ that are in $K$ but not in $K^{\prime}$, we have $y_{i}-h_{i}^{A}\left(G^{B(K)}\right)<0$. The third inequality is implied by the 'only-if' part of the Lemma. The 'if-part' of the Lemma then shows that the coalition $K^{\prime}$ is also able to block allocation $A$. Finally, we define $\breve{s}:=G^{A}-G^{B(K)}>0$, implying that $\breve{K}=\left\{i \in N: s_{i}^{A} \geq \breve{s}\right\}=K^{\prime}$. Thus, the requested threshold level for the Moulin sacrifices is given by $\breve{s}$.

\section{A 3: Proof of Proposition 2}

We first show that, for any subgroup $K$, there exists an $\varepsilon(K)>0$ such that all Pareto-optimal allocations $A$ which imply $s_{i}^{A} \in\left[s^{E}-\varepsilon(K), s^{E}+\varepsilon(K)\right]$ cannot be blocked by coalition $K$. Otherwise, there would exist a sequence $\left(A_{j}\right)_{j \in \mathbb{N}}$ of Pareto-optimal allocations (and corresponding sequences of Moulin sacrifices $\left(s_{i}^{A_{j}}\right)_{j \in \mathbb{N}}$ and utility levels $\left(u_{i}^{A_{j}}\right)_{j \in \mathbb{N}}$ with $\lim _{j \rightarrow \infty} s_{i}^{A_{j}}=s^{E}$ and $\lim _{j \rightarrow \infty} u_{i}^{A_{j}}=u^{E}$ for each $\left.i=1, \ldots, n\right)$ such that, for all $j \in \mathbb{N}$, coalition $K$ could block allocation $A_{j}=\left(x_{i}^{A_{j}}\right)_{j \in \mathbb{N}}$. Then the Lemma implies that $\hat{Y}_{K}^{A_{j}}<Y_{K}$ for all $j \in \mathbb{N}$. As $\lim _{j \rightarrow \infty} u_{i}^{A_{j}}=u^{E}$, this gives $\hat{Y}_{K}^{E}=\lim _{j \rightarrow \infty} \hat{Y}_{K}^{A_{j}} \leq Y_{K}$, which-again according to the Lemma-means that coalition $K$ could attain the same utility levels for all its members by standing alone and choosing a blocking allocation with public good supply $G^{B(K)}$. Since, trivially, $G^{B(K)}>G^{E}-s^{E}$, the allocation in which the coalition $K$ chooses $B(K)$ and all countries $i \notin K$ enjoy private consumption $y_{i}$ is feasible and-as $h_{i}^{A}\left(G^{B(K)}\right)<y_{i}$ for all $i=1, \ldots, n$-would entail a Pareto-improvement over $E$. This, however, contradicts the Pareto-optimality of $E$. Thus, a sequence $\left(A_{j}\right)_{j \in \mathbb{N}}$ of blockable allocations converging to $E$ cannot exist, implying that a critical value $\varepsilon(K)>0$ with the required 
property exists for any coalition $K$. Taking the minimum of all $\varepsilon(K)$ over the finitely many subgroups of $N$ then completes the proof.

\section{A 4: Proof of Proposition 3}

Given some coalition $K$, let $\underline{s}(K)=s^{E}+\left(\bar{G}^{E}-\bar{G}^{E(K)}\right)$ be the threshold level for Moulin sacrifices, where $\bar{G}^{E}$ and $\bar{G}^{E(K)}$ are the egalitarian-equivalent public good supply levels for the EMS $E$ of all countries and for the standalone equal Moulin sacrifice solution $E(K)$ of group $K$, respectively. Now consider any allocation $A$ for which $s_{i}^{A}>\underline{s}(K)$ holds for each country $i \in K$. Then we have

(A-2) $\bar{G}_{i}^{A}=G^{A}-s_{i}^{A}<G^{A}-\left[s^{E}+\left(\bar{G}^{E}-\bar{G}^{E(K)}\right)\right]=G^{A}-\left[G^{E}-\bar{G}^{E}+\left(\bar{G}^{E}-\bar{G}^{E(K)}\right)\right]=\bar{G}^{E(K)}$.

In (A-2), the first equality sign and the second one follow from the definition of the Moulin sacrifices, the inequality sign from the assumption $s_{i}^{A}>\underline{s}(K)$ and the definition of $\underline{s}(K)$, and the last equality sign from $G^{A}=G^{E}$ because, with CEP preferences, public good supply is the same in all Pareto-optimal allocation. From $\bar{G}_{i}^{A}<\bar{G}^{E(K)}$, which is established by (A-2), it follows that $u_{i}\left(x_{i}^{E(K)}, G^{E(K)}\right)=u_{i}\left(y_{i}, \bar{G}^{E(K)}\right)>u_{i}\left(y_{i}, \bar{G}^{A}\right)=u_{i}\left(x_{i}^{A}, G^{A}\right)$ for every $i \in K$ so that all members of coalition $K$ attain a higher utility in their standalone allocation $E(K)$ than in the allocation $A$. Therefore, coalition $K$ is able to block allocation $A$.

Finally, $\bar{G}^{E(K)}<\bar{G}^{E}$ and thus the inequality $\underline{s}(K)>s^{E}$ hold, since otherwise the feasible allocation, in which private consumption is $x_{i}^{E(K)}$ for all $i \in K$ and $y_{i}$ for all $i \notin K$ and public good supply is $G^{E(K)}$, would Pareto-dominate allocation $E$, which is a contradiction to the Paretooptimality of $E$.

\section{A 5: Proof of Proposition 4}

We rank countries in descending order of their Moulin sacrifices, i.e. $s_{1}^{A} \geq \cdots \geq s_{n}^{A}$. Then initial endowment is shifted from some country $j$ to another country $l>j$ such that the Moulin sacrifice of country $j$ decreases and that of country $l$ increases while the ranking of the sacrifice levels is preserved. Given the technological assumption T1, the allocation $A$ remains feasible after such a redistribution of the initial endowment, since all private consumption levels are kept constant. For any $k=1, \ldots, n$, now let total income of subgroup $K(k)=\{1, \ldots, k\}$ be denoted by $Y_{k}$ before 
and by $\tilde{Y}_{k}$ after the transfer. Obviously, $\tilde{Y}_{k}=Y_{k}$ holds for all $k<j$ and all $k \geq l$, and $\tilde{Y}_{k}<Y_{k}$ for all $k$ with $j \leq k<l$. The Lemma then implies that no coalition $K(k)$ is able to block the original allocation $A$ after the change if no coalition $K(k)$ could do so under the initial income distribution. Proposition 1, however, says that some of these coalitions $K(k)$ (with the relatively highest Moulin sacrifices) should have been able to block $A$ if this allocation can be blocked at all. This shows that allocation $A$ remains in the core after the income redistribution.

\section{References}

Allouch, N. (2010), A Core Equivalence Condition in a Public Goods Economy, Journal of Public Economic Theory 12, 857-870.

Barrett S. (1994), Self-Enforcing International Environmental Agreements, Oxford Economic Papers $46,878-894$.

Bergstrom, T. and Cornes, R. (1983), Independence of Allocative Efficiency from Distribution in the Theory of Public Goods, Econometrica 51, 1753-1765.

Bergstrom, T., Blume, L. and Varian, H. (1986), On the Private Provision of Public Goods, Journal of Public Economics 29, 25-49.

Bretschger, L. (2013), Climate Policy and Equity Principles: Fair Burden Sharing in a Dynamic World, Environment and Development Economics (forthcoming).

Buchholz, W. and Peters, W. (2008), Equal Sacrifice and Fair Burden-Sharing in a Public-Goods Economy, International Tax and Public Finance 15, 415-414

Carraro, C. and Siniscalco, D. (1993), Strategies for the International Protection of the Environment, Journal of Public Economics 52, 309-328.

Chander, P. and Tulkens, H. (1995), A Core-Theoretic Solution for the Design of Cooperative Agreements on Transfrontier Pollution, International Tax and Public Finance 2, 279-294.

Chander, P. and Tulkens, H. (1997), The Core of an Economy with Multilateral Environmental Externalities, International Journal of Game Theory 26, 379-401.

Chander, P. and Tulkens, H. (2009), Cooperation, Stability, and Self-Enforcement in International Environmental Agreements: A Conceptual Discussion, in: R. Guesneries and H. Tulkens (eds.), The Design of Climate Policies, CESifo Seminar Series, MIT Press, Boston, 165-186.

Cornes, R. (1992), Duality and Modern Economics, Cambridge University Press, Cambridge, UK, et al. 
Cornes, R. and Sandler, T. (1996), The Theory of Externalities, Public Goods and Club Goods, $2^{\text {nd }}$ ed., Cambridge University Press, Cambridge, UK, et al.

Endres, A. and Finus, M. (1999), International Environmental Agreements: How the Policy Instrument Affects Equilibrium Emissions and Welfare, Journal of Institutional and Theoretical Economics 155, 527-550.

Eyckmans (2012), Review of Applications of Game Theory to Global Climate Agreements, Review of Business and Economic Literature 57, 122-143.

Finus, M. (2001), Game Theory and International Environmental Cooperation, Edward Elgar, Cheltenham.

Finus, M. (2008), Game Theoretic Research on the Design of International Environmental Agreements: Insights, Critical Remarks, and Future Challenges, International Review of Environmental and Resource Economics 2, 29-67.

Finus, M. and Rundshagen, B. (2006), A Micro-Foundation of Core-Stability in Positive Externality Coalition Games, Journal of Institutional and Theoretical Economics 162, 329-346.

Foley, D. (1970), Lindahl's Solution and the Core of an Economy with Public Goods, Econometrica 38, 66-72.

Hahn, K. and Gilles, R. P. (1998), Efficient Egalitarian-Equivalence and the Core of an Economy with Public Projects, Economics Letters 60, 173-178.

Intergovernmental Panel on Climate Change IPCC (2014), Fifth Assessment Report (AR 5), Climate Change Mitigation 2014: Mitigation of Climate Change, Chapter 3: Social, Economic asnd Ethical Concepts and Methods, Chapter 4: Sustainable Development and Equity.

Kolm, S.-Ch. (2006), Reciprocity: Its Scope, Rationales and Consequence, in: S.-Ch. Kolm and J. M. Ythier (eds.), The Handbook of the Economics of Giving, Altruism and Reciprocity, Vol. 1, Elsevier, Amsterdam et al.

Lange, A., Vogt, C. and Ziegler, A. (2007), On the Importance of Equity in International Climate Policy: An Empirical Analysis, Energy Economics 29, 545-569.

Lindahl, E. (1919), Die Gerechtigkeit der Besteuerung: Eine Analyse der Steuerprinzipien auf Grundlage der Grenznutzentheorie, Gleerupska Universitetsbokhandeln, Lund.

LeBreton, M., Moreno-Ternero, J. D., Savvateev, A, and Weber, S. (2013), Stability and Fairness in Models with a Multiple Membership, International Journal of Game Theory 42, 673-694.

Mas-Colell, A. and Silvestre, J. (1989), Cost Share Equilibria: A Lindahlian Approach, Journal of Economic Theory 47, 239-256. 
Moulin, H. (1987), Egalitarian Equivalent Cost-Sharing of a Public Good, Econometrica 55, 963977.

Moulin, H. (1995), Cooperative Microeconomics: A Game-Theoretic Introduction, Princeton University Press, Princeton, NJ.

Myles, G. D. (1995), Public Economics, Cambridge University Press, Cambridge, UK, et al.

Pearson, Ch. S. (2011), Economics and the Challenge of Global Warming, Cambridge University Press, Cambridge, UK, et al.

Posner, E. and Weisbach, D. (2010), Climate Change Justice, Princeton University Press, Princeton NJ.

Ray, D. (2007), A Game-Theoretic Perspective on Coalition Formation, Oxford University Press, Oxford, UK.

Ringius, L., Torvanger, A. and Underdal, A. (2002), Burden Sharing and Fairness Principles in international Climate Policy, International Environmental Agreements: Politics, Law and Economics 2, 1-22.

Sandler, T. (2004), Global Collective Action, Cambridge University Press, Cambridge, UK.

Weber, S. and Wiesmeth, H. (1991), The Equivalence of Core and Cost Share Equilibria in an Economy with a Public Good, Journal of Economic Theory 54, 180-197.

Wicksell, K. (1896), Finanztheoretische Untersuchungen: Nebst Darstellung und Kritik des Steuerwesens Schwedens, Gustav Fischer, Jena.

Wiesmeth, H. (2012), Environmental Economics: Theory and Policy in Equilibrium, Springer, Berlin et al. 